\title{
Effects of NMDA receptor blockade on behaviors differentially affected by fimbria/fornix and amygdala lesions
}

\author{
LESLEY STEVENS, MATTHEW SHAPIRO, and NORMAN M. WHITE \\ McGill University, Montreal, Quebec, Canada
}

\begin{abstract}
We studied the effects of MK-801, a noncompetitive NMDA receptor antagonist, on acquisition and expression of the food conditioned cue preference (CCP) in the eight-arm radial maze. In this task, food-deprived rats are confined on alternate days in one arm of a radial maze with food and in another arm with no food. After several such training trials, they are given a choice between the two arms, both of which are empty. Normal rats spend more time in the arm that formerly contained food. We previously showed that this CCP is eliminated by lesions of the lateral nucleus of the amygdala. A single 10min session of preexposure to the maze with no food retards acquisition of the CCP. This retardation is eliminated by fornix lesions, suggesting that hippocampus-based learning about the environment during the preexposure session suppresses subsequent amygdala-based CCP learning. In the present experiment, rats that received MK-801 before a preexposure session exhibited CCPs comparable to those for animals that had not experienced preexposure. We attribute this effect to the prevention of hippocampus-based learning during the preexposure due to NMDA receptor blockade. In other groups of rats, MK-801 given before the training trials or before the test trial eliminated the CCP in rats that had not received preexposure to the maze. The prevention of both acquisition and expression of the amygdala-based food CCP by MK-801 may distinguish the memory-related function of NMDA receptors in the amygdala from that of similar receptors in the hippocampus.
\end{abstract}

Different forms of learning and memory are probably mediated by neural systems that both function independently and interact with each other in humans (Cohen \& Squire, 1980; Damasio \& Tranel, 1990; Huber, Shuttleworth, \& Freidenberg, 1989; Knowlton, Squire \& Gluck, 1994; Milner, 1985; Morris et al., 1988; Moscovitch, 1994; Sahakian et al., 1988; Scoville \& Milner, 1957; Squire \& Zola-Morgan, 1991) and animals (Black, Nadel, \& O'Keefe, 1977; Blodgett \& McCutchan, 1947; Dickinson \& Dawson, 1989; Eichenbaum, Fagan, \& Cohen, 1986; Erickson \& Patel, 1969; Gaffan, 1974; Hirsh, 1974; Mishkin, Malamut, \& Bachevalier, 1984; Mishkin \& Petri, 1984; O'Keefe \& Nadel, 1978; O’Keefe, Nadel, Keightley, \& Kill, 1975; Orbach, Milner, \& Rasmussen, 1960; Packard, Hirsh, \& White, 1989; Packard \& McGaugh, 1992; Tolman, 1949). Three such systems have been defined (McDonald \& White, 1993), in which the hippocampus, the amygdala, and the dorsal striatum (caudate-putamen) are important, or central, structures. According to this scheme, the hippocampus system mediates memories that involve spatial, or relational, learning (Eichenbaum, 1992; Eichenbaum, Cohen, Otto, \& Wible, 1992; Hirsh, 1974; O'Keefe \& Nadel, 1978); the amygdala system mediates associations of rewarding or aversive affective states with neutral cues (Cador, Rob-

Correspondence should be addressed to N. M. White, Department of Psychology, McGill University, 1205 Dr Penfield Ave., Montreal, PQ, Canada H3A 1B1 (e-mail: nwhite@psych.mcgill.ca). bins, \& Everitt, 1989; M. Davis, 1992; Hiroi \& White, 1991 b; Jones \& Mishkin, 1972; LeDoux, 1993; Weiskrantz, 1956; White \& McDonald, 1993), and the dorsal striatum system acquires stimulus-response tendencies (McDonald \& White, 1995a; Mishkin et al., 1984; Packard \& McGaugh, 1992; Petri \& Mishkin, 1993; Wiener, 1993).

One way of studying these proposed systems is to examine experimental situations in which they appear to promote opposing behavioral tendencies. For example, an improvement in performance on simple stimulus-response tasks following lesions of the hippocampus or fornix has been reported several times (e.g., Eichenbaum, Fagan, Matthews, \& Cohen, 1988; Isaacson \& Douglas, 1961; Jackson \& Strong, 1969; O'Keefe et al., 1975; Orbach et al., 1960). White and McDonald (1993) reported that acquisition of a conditioned cue preference (CCP, also known as the conditioned place preference) on the radial maze is impaired by lesions of the amygdala but is apparently facilitated by fornix lesions.

The CCP task usually includes three phases (Figure 1). In Phase 1, the rats are preexposed to the apparatus with no food available, usually for one or more short periods. In Phase 2, the rats are trained by confining them in a location that contains food and in a location that does not contain food. The food and no-food trials are usually given on separate days and are repeated several times. In Phase 3, the rats are given a choice between the two locations, neither of which contains food. A CCP is expressed as a preference for the location that formerly contained food, 
Phase of Experiment

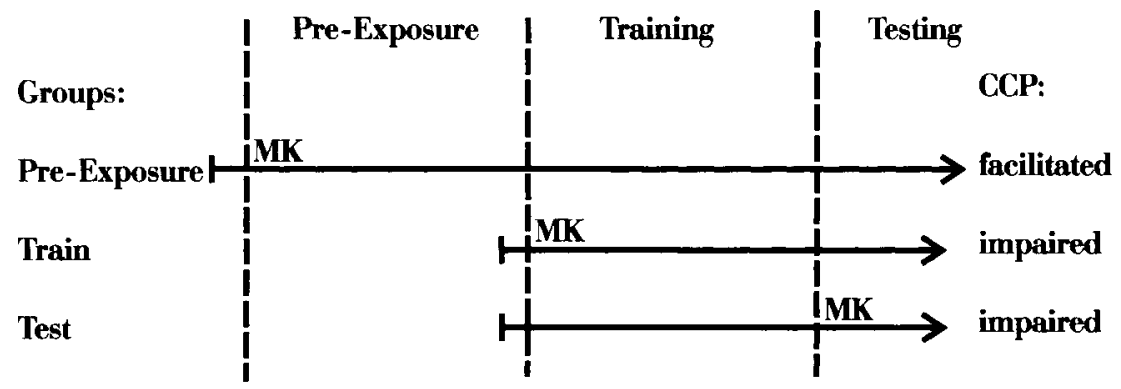

\begin{abstract}
Figure 1. Diagram of experimental design. The three phases of the $\mathrm{CCP}$ procedure are shown at the top: preexposure, training, and testing. See text for details of the procedure in each phase. The three sequences of experimental treatment are represented by horizontal arrows with the name of the treatment in the column on the left. The rats in the preexposure groups received MK-801 or saline injections before the preexposure session and no further drug treatments. The rats in the training and testing groups did not receive preexposure to the maze. Those in the training groups received injections of MK-801 or saline before each training session; those in the testing groups received MK-801 or saline before the testing session.
\end{abstract}

measured as the difference in the time the rats choose to spend in the two locations.

Because the rats experience the food while confined in the arms, the CCP is thought to involve stimulus-reward learning (McDonald \& White, 1995b). CCP learning is impaired by lesions of the lateral parts of the amygdala, suggesting the involvement of this structure in this type of learning. In contrast, CCP learning is facilitated by fornix lesions, suggesting that this structure, together with the hippocampus, is not required for CCP learning. Instead, the latter finding suggests that the hippocampus system may mediate a form of learning that competes with, or otherwise interferes with, amygdala-based CCP learning (McDonald \& White, 1993).

The facilitation of CCP learning by fornix/fimbria lesions interacts with exposure of rats to the maze prior to the start of CCP training (McDonald \& White, 1995a). Normal rats that did not experience preexposure to the maze prior to training acquired the $\mathrm{CCP}$ faster than normal rats that received a single 10 -min period of preexposure. Rats that were placed on a radial maze in a different room for $10 \mathrm{~min}$ prior to training also acquired the $\mathrm{CCP}$ faster than normal rats that received preexposure in the same room. This suggests that acquisition of specific information about the environment, possibly in the form of a spatial (O'Keefe \& Nadel, 1978) or cognitive (Hirsh, 1980) map, presumably including the cues that are subsequently conditioned, interferes with and retards the conditioning process during $\mathrm{CCP}$ training.

The acquisition of spatial information about the maze environment during preexposure may be impaired in rats with fornix/fimbria lesions, and this could account for their facilitated CCP learning. However, when fornix/ fimbria lesions were made after preexposure but before training, or after training but before testing, they had no effect on subsequent CCP learning, which occurred normally. This suggests that the fornix is required for acquiring environmental information during preexposure, but that it is not required for this information to impede subsequent amygdala-based CCP learning.

One purpose of the present experiment was to test the hypothesis that hippocampus-based learning occurring during the preexposure period subsequently retards acquisition of the CCP. We did this by attempting to block hippocampal learning during the preexposure session with the noncompetitive $N$-methyl-D-aspartate (NMDA) antagonist, MK-801 ((+)-10,11-dihydro-5-methyl-5H dibenzo [a,d] cycloheptene-5,10 imine). Several lines of evidence suggest that this drug may block hippocampusbased spatial or relational learning.

First, NMDA antagonists impair performance on memory tasks that are affected by lesions of the hippocampus system. Aminophosphonovaleric acid (APV), a competitive NMDA antagonist, impaired rats' ability to locate a submerged (hidden) platform in the water maze (Morris, Anderson, Lynch, \& Baudry, 1986), a task that is also impaired by hippocampal lesions (Morris, Garrud, Rawlins, \& O'Keefe, 1982; Sutherland \& Rudy, 1988; Sutherland, Whishaw, \& Kolb, 1983). The same dose of the same drug had no effect on the rats' ability to locate a visible platform, a task that is unaffected by lesions of the hippocampus system. MK-801 also impairs performance on the hidden-platform task in the water maze (Kant, Robinson, \& D'Angelo, 1991; Robinson, Crooks, Shinkman, \& Gallagher, 1989) and on the component of the four/eight task on the eight-arm radial maze (the same four arms contain food on every trial) (Shapiro \& Caramanos, 1990; Shapiro \& O'Connor, 1992) that is impaired by lesions of the fornix (Packard, 1989). MK-801 also impairs performance on an olfactory discrimination 
learning task (Staubli, Thibault, DiLorenzo, \& Lynch, 1989), which is impaired by hippocampus-system lesions (Eichenbaum et al., 1986).

Second, long-term and primed-burst potentiation (LTP and PBP) are forms of easily induced synaptic plasticity that may reflect a mechanism of information storage in hippocampus (Bliss \& Lynch, 1988; Lynch, 1986; McNaughton \& Morris, 1987). LTP induction in CA1 and dentate gyrus of the hippocampus requires NMDA receptors, which are concentrated in these regions (Collingridge, Kehl, \& McLennan, 1983; Grover \& Teyler, 1990). LTP maintenance and expression, however, do not require NMDA receptor activation (Brown, Chapman, Kairiss, \& Keenan, 1988; Muller, Larson, \& Lynch, 1989).

The induction of LTP and PBP in hippocampus and hippocampus-dependent spatial learning may share common mechanisms. Intraventricular administration of APV blocks both LTP induction and spatial learning in the water maze (Morris et al., 1986). Impairment of spatial learning is correlated with hippocampal APV concentration and with the blockade of hippocampal LTP (Butcher, Hamberger, \& Morris, 1991; S. Davis, Butcher, \& Morris, 1992). MK-801 blocks LTP induction in vitro (Coan, Saywood, \& Collingridge, 1987; Kemp, Priestly, \& Woodruff, 1986; Swartzwelder, Ferrari, Anderson, \& Wilson, 1989) and in vivo (Abraham \& Mason, 1988). This drug impairs place learning in the water maze but does not impair spatial memory performance in rats trained before the drug is given (Heale \& Harley, 1990; Robinson et al., 1989). MK-801 also impairs spatial learning, but not performance, in the radial maze (Caramanos \& Shapiro, 1994) at doses that attenuate PBP (Hargreaves, Cote, \& Shapiro, 1997).

Although hippocampal LTP displays the highest magnitude of change following stimulation, LTP can be recorded in all limbic areas (Racine, Milgram, \& Hafner, 1983). Furthermore, NMDA receptors are also expressed in high concentrations in the amygdala (Miserendino, Sananes, Melia, \& M. Davis, 1990). LTP can occur in amygdala brain slices or in vivo following tetanic stimulation of the part of the medial geniculate nucleus that projects to the lateral nucleus of the amygdala, and this induction can be blocked by NMDA antagonists (Clugnet \& LeDoux, 1990; M. Davis, Falls, Campeau, \& Kim, 1993; Kim, Campeau, Falls, \& M. Davis, 1993).

Several studies also suggest that NMDA receptor antagonists impair learning of tasks that are impaired by lesions of the amygdala, including conditioned taste aversion (Willner, Gallagher, Graham, \& Crooks, 1992; Yamamoto \& Fujimoto, 1991) and fear conditioning (Fanselow, 1993; Miserendino et al., 1990). Given the evidence that acquisition and expression of the CCP are impaired by lesions of the lateral nucleus of the amygdala (Hiroi \& White, 1991b; White \& McDonald, 1993), we attempted to extend this pattern to the effects of MK801 on acquisition and expression of the CCP. The lesion evidence suggesting that the hippocampus system is not involved in these processes (already discussed) implies that any effects of MK-801 on acquisition or expression of the CCP are probably not due to its action on memoryrelated processes that occur in the hippocampus.

In summary, there were three experimental groups, each intended to test a hypothesis about the effects of blocking NMDA-based neuroplasticity at different times in the CCP procedure (Figure 1). Rats in the preexposure group received MK- 801 before preexposure to the maze. In this condition, the control rats that received saline injections were not expected to exhibit CCPs due to hypothesized hippocampal learning during the preexposure session. The rats that received MK-801 were expected to exhibit a CCP if this substance blocked learning about the spatial environment during the preexposure session.

Rats in the training and testing conditions did not receive any preexposure to the maze (Figure 1). In the training condition, MK- 801 was administered before each CCP training session; in the testing condition, the drug was given before the test session. In both of these conditions, rats that received saline injections were expected to exhibit CCPs because they did not receive preexposure to the maze environment and, so, lacked the opportunity to acquire information about it. This allowed assessment of the effects of MK-801 on acquisition and expression of the CCP, which is known from the lesion data to be amygdala-based. On the assumption that NMDA receptors in the amygdala have memory-related functions similar to those in hippocampus, pretraining MK-801 was expected to block acquisition of the CCP and pretesting MK-801 was not expected to affect expression of the CCP.

\section{METHOD}

\section{Subjects}

The subjects were 48 female Sprague-Dawley rats, housed individually in single cages and maintained on a 12:12-h light:dark cycle. The rats weighed $250-275 \mathrm{~g}$ at the start of the experiment, and they were maintained on a food-deprivation schedule that reduced them to $85 \%$ of these weights.

\section{Apparatus}

An eight-arm radial maze (made of wood, painted gray, and elevated $60 \mathrm{~cm}$ from the floor) was used. The center platform was $40 \mathrm{~cm}$ in diameter; each arm was $60 \mathrm{~cm}$ long and $9 \mathrm{~cm}$ wide. Six of the eight arms were blocked with rectangular gray wooden blocks $(35 \times 19 \times 8.5 \mathrm{~cm})$ that fit into the entrances of the arms. Similar wooden blocks with panels $(35 \times 35 \mathrm{~cm})$ facing the ends of the arms were used to confine the rats to the ultimate $30 \mathrm{~cm}$ of their assigned arms. The maze was located in the center of a $2.9 \times 2.9 \mathrm{~m}$ room with no windows. Posters were placed on two walls and a large black plank rested vertically in the corner formed by these two walls. The experimenter sat in a chair in the opposite corner. Another wall supported a bookshelf with a few random objects. A small table and the door were on the fourth wall.

\section{Drug}

MK-801 (dizocilpine: (+)-10,11-dihydro-5-methyl-5H-dibenzo [a,d]-cycloheptene-5,10-imine), obtained from Sigma Co., was dissolved in physiological saline $(0.0625 \mathrm{mg} / \mathrm{kg})$ and injected intraperitoneally $60 \mathrm{~min}$ before testing, as indicated in the Procedure section below. The saline vehicle was injected in the control groups 


\section{Procedure}

During the initial food-deprivation procedure, the rats were handled for $10 \mathrm{~min}$ per day for 4 days. On each of these days, each rat was given sufficient rat chow to maintain its body weight at $85 \%$ of its value on the lst day of the experiment. The rats were also given 20 Froot Loops per day in their home cages. For the last 2 days of handling, the rats were habituated to the drug. On each of these days, they were injected with MK-801 and placed for $30 \mathrm{~min}$ on a radial maze located in a different room from the one used for the experiment. This maze contained neither food nor blockers.

Two opposite arm positions on the radial maze were assigned to each rat so that all positions were represented in each experimental group. For each rat, one of the two assigned positions was designated the "paired" position (the position that contained food), and the other was the "unpaired" position. The entire maze was rotated daily by one arm position to the left so that a different arm of the maze occupied each position on each experimental trial. This prevented the use of intramaze cues to distinguish between the arms.

The treatments given each group are illustrated in Figure 1. On the day following the handling and food-deprivation period, the rats in the preexposure groups were injected with either MK-801 or saline and placed on the maze $60 \mathrm{~min}$ later for a 10 -min preexposure period. The two arms assigned to each animal were open; the other six maze arms were blocked. There was no food on the maze. Each rat was placed on the central platform and allowed to move freely. Records were kept of the times of entry into and exit from the arms. The rats in the training and testing groups were not preexposed to the maze, and they did not receive any injections at this time. They were given their first training trial on the day following the end of the handling routine.

All rats received four training trials. The rats in the training groups received either MK- $80 \mathrm{l}$ or saline injections before each training session (a total of eight injections). The rats in the preexposure and test groups did not receive any injections at this time. Each training trial comprised two sessions and took place over 2 days. In each group, half of the rats were confined for $30 \mathrm{~min}$ in their paired arm on the 1st day and in their unpaired arm on the 2nd day. This order was reversed for the other half of the rats in each group. Paired arms contained 50 Froot Loops, placed at the end of the arm so that the rat faced the cues beyond it while eating. The number of Froot Loops remaining in the arms at the end of the session was counted. Unpaired arms were empty.
The final session was the test trial; the procedure was identical to that for the preexposure day, except that it lasted for $20 \mathrm{~min}$. The rats in the test groups received either MK-801 or saline injections $60 \mathrm{~min}$ before these trials. The rats in the preexposure and training groups did not receive any injections at this time.

\section{RESULTS}

The results for the six groups are shown in Figure 2. The effects of NMDA blockade depended on the point in the experimental procedure at which MK- 801 was injected. The group that received MK- 801 before preexposure (followed by four training trials) exhibited a large CCP; its saline control group did not exhibit a CCP. The group that received MK-801 before each of its four training trials failed to exhibit a CCP; its control did acquire this behavior. Similarly, the group that received MK-80 1 before its test trial (after four training trials) also failed to exhibit a CCP, whereas its saline control group acquired and expressed the behavior.

Two rats in the group that received MK- 801 before training were eliminated from the statistical analysis. These animals did not appear to tolerate the injections well and were hypoactive during the test trials, failing to enter both of their assigned maze arms at least once. Accordingly, this group had 6 subjects; all other groups had 8 . As can be seen from the analysis below, the activity levels of the remaining subjects in this group were similar to those of the rats in other groups, including the saline groups.

A three-way analysis of variance (ANOVA) on the time spent in the paired and unpaired locations with injection time (preexposure vs. training vs. testing), drug (MK-801 vs. saline), and side (paired vs. unpaired; repeated measure) revealed a significant three-way interaction among the factors $[F(2,40)=4.18, p<.03]$. Planned comparisons (all $d f \mathrm{~s}=1,40$ ) were used to compare the CCPs observed in each of the experimental con-

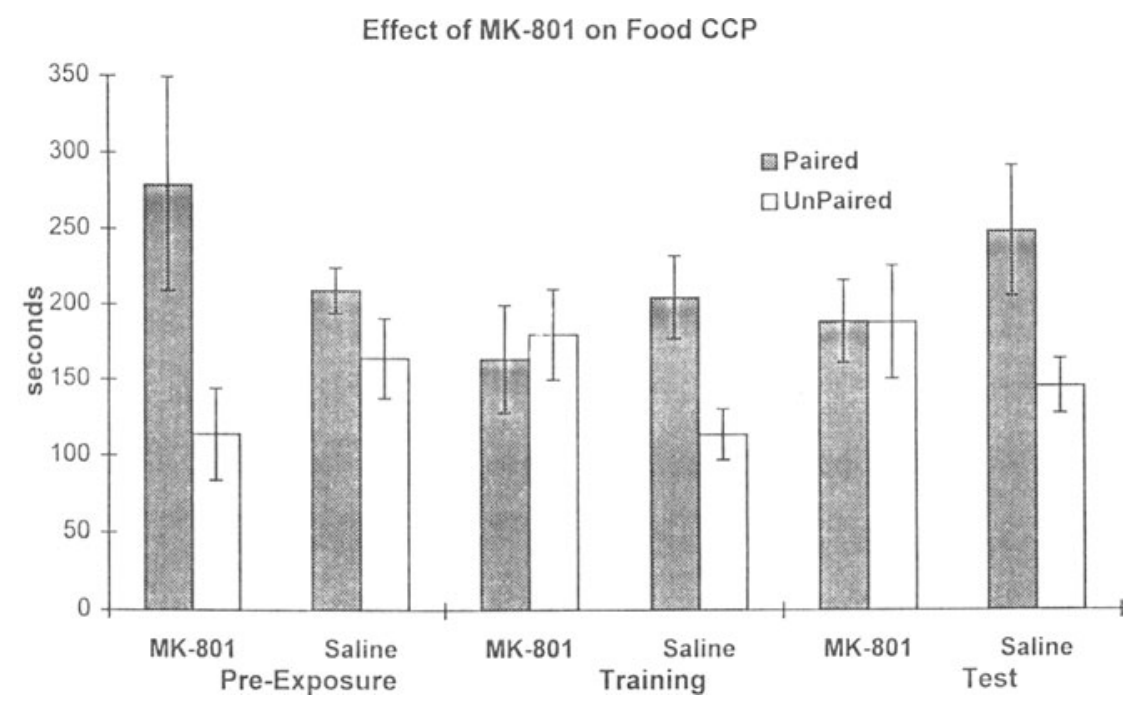

Figure 2. Effects of MK-801 and saline administered $60 \mathrm{~min}$ before experimental phase indicated on abscissa. Bars represent mean times spent during a 20 -min test in radial maze locations previously paired or not paired with food. Standard errors of the means are shown. 
ditions. In the preexposure condition, there was a significant difference between the amount of time spent in the paired and unpaired locations for the MK-801 group $(F=17.42, p<.01)$, but no significant CCP for the saline group $(F=1.29)$. In the training condition, there was no significant difference for the MK-801 group $(F=0.13)$, but the saline group exhibited a significant $\operatorname{CCP}(F=5.28, p<.03)$. In the test condition, the MK801 group failed to exhibit a significant $\operatorname{CCP}(F=0.99)$, but the difference between the sides was significant for the saline group $(F=4.46, p<.03)$.

A comparison of the behavior of the rats in the three saline groups provides a replication of the previously demonstrated effects of preexposure to the maze environment (McDonald \& White, 1995a) on subsequent CCP learning. Although the rats in all three groups received four training trials, the rats that received $10 \mathrm{~min}$ of preexposure did not learn the CCP, whereas the rats in the two groups (training and testing) that did not have this experience both exhibited significant CCPs. Preexposure to the maze and its environment suppresses subsequent acquisition of the CCP.

The number of Froot Loops consumed during each pairing was summed over the four training trials for each group. These values are shown in Table 1. A two-way ANOVA on these data (injection time vs. drug) revealed a significant interaction between the two factors $[F(2,40)=5.16, p<.01]$. The means for the drug and saline groups at each injection time were compared using LSD tests. For the preexposure groups, the MK801 animals ate significantly less during their subsequent pairing sessions than did the rats in their saline control group $[t(14)=2.95, p<.02]$. Nevertheless, the rats in the MK-801 group acquired a CCP, whereas those in the saline group did not. For the pretraining groups, the MK-801 rats ate significantly less than did their saline controls $[t(12)=2.37, p<.05]$. In this case, the saline animals acquired a CCP, whereas the drugged animals did not. There was no significant difference between the amounts of food consumed by the rats in the pretest groups $[t(14)=1.24]$, although the rats in the saline group exhibited a CCP and those in the MK-801 group did not. The lack of a consistent relationship between food consumption and the presence of a CCP suggests that differences in amounts eaten were not a major determinant of the tendency to exhibit a CCP, within the range of consumption observed.

Estimates of the activity levels of the rats on the preexposure and test trials were made by counting the num-

Table 1

Mean Numbers and SEMs of Froot Loops Consumed During Training Trials

\begin{tabular}{lcrrrr} 
& \multicolumn{2}{c}{ MK-801 } & & \multicolumn{2}{c}{ Saline } \\
\cline { 2 - 4 } \cline { 5 - 6 } \multicolumn{1}{c}{ Group } & $M$ & $S E M$ & & $M$ & $S E M$ \\
\hline Preexposure* & 42.5 & 10.7 & & 91.8 & 12.3 \\
Training* & 47.0 & 13.0 & 86.6 & 14.4 \\
Test & 178.2 & 5.1 & 157.5 & 12.9 \\
\hline${ }^{*} p<.05$. & & & &
\end{tabular}

Table 2

Mean Numbers and SEMs of Arm Entries on Test Trials

\begin{tabular}{|c|c|c|c|c|}
\hline \multirow[b]{2}{*}{ Group } & \multicolumn{2}{|c|}{ MK-801 } & \multicolumn{2}{|c|}{ Saline } \\
\hline & $M$ & $S E M$ & $M$ & $S E M$ \\
\hline Preexposure & 15.0 & 0.92 & 21.5 & 3.05 \\
\hline Training & 19.5 & 4.03 & 16.3 & 1.81 \\
\hline Test* & 32.5 & 4.46 & 17.8 & 1.87 \\
\hline
\end{tabular}

${ }^{*} p<.01$.

ber of times they entered an arm (either paired or unpaired) during the 20 -min session. For the rats given preexposure, the mean number of arm entries made during this session was 14.2 for the MK-801 group and 8.0 for the saline group. Although the difference between these means failed to reach significance $[t(14)=1.48]$, the drugged rats were somewhat more active than the saline rats. Since the rats are thought to learn about the spatial environment of the maze by exploring it during this session, the direction of the difference suggests that, if anything, the rats that received MK- 801 could have acquired more of this type of information than did the salinetreated rats. This should have resulted in more suppression of the subsequent CCP learning. The fact that the MK-801-treated rats exhibited a larger CCP than did the saline animals is consistent with the hypothesis that the drug acted to block this form of learning.

The arm entries for the test trials are shown in Table 2. A two-way ANOVA (injection time vs. drug) revealed a significant interaction between the two variables $[F(2,42)$ $=7.90, p<.01]$. The means for the drug and saline groups at each injection time were compared using LSD tests. There were no significant differences between the mean number of arm entries for the MK-801 and saline groups in the preexposure or pretraining groups. However, in the pretest condition, the rats in the MK-801 group made significantly more entries than did those in their saline control group $[t(14)=3.89, p<01]$. Thus, although MK-801 increased the activity levels of rats under its influence, these effects did not consistently influence CCP learning. These observations are consistent with others showing that, within certain limits, activity levels do not affect either acquisition (Carr, Phillips, \& Fibiger, 1988) or expression (Hiroi \& White, 1991a) of the CCP.

\section{DISCUSSION}

Administration of MK-801 before a 10-min period of preexposure to the radial maze environment facilitated subsequent acquisition of the food CCP, relative to a group of rats that experienced preexposure but did not receive MK-801. Preexposure is known to suppress acquisition of the CCP (McDonald \& White, 1995a, and compare the present saline-preexposure group with the saline training and test groups that did not experience preexposure), and this suppression is eliminated by fornix lesions (McDonald \& White, 1995a; White \& McDonald, 1993). These findings have been interpreted as 
suggesting that the rats acquire information about the maze environment during preexposure, possibly in the form of a spatial or cognitive map, and that the presence of this information during the subsequent training trials acts to suppress acquisition of the CCP. Since fornix lesions are known to prevent this form of learning (Eichenbaum, Stewart, \& Morris, 1990; Gaffan \& Harrison, 1989; Olton \& Papas, 1979; Olton \& Samuelson, 1976; Sutherland \& Rodriguez, 1989), rats with these lesions may fail to acquire this information during preexposure, allowing them to learn the CCP as quickly as normal animals that have not experienced preexposure. The present findings are consistent with this interpretation, given the evidence reviewed in the introduction suggesting that MK-801 may prevent hippocampus-based learning by blocking NMDA receptors. The acquisition of a CCP by the rats that received this drug before preexposure is predicted by the hypothesis that it acted to prevent learning during this period, subsequently allowing the rats to acquire the CCP as if they had not been preexposed.

The suppression of CCP learning produced by preexposure to the maze environment resembles the phenomenon of latent inhibition (Hall \& Pearce, 1979; Lubow, 1973), the retardation of conditioning by preexposure to the conditioned stimulus. Although the maze environment explored by the rats in the present experiment included the to-be-conditioned stimuli, they were not experienced as individual cues but as components of a spatial map of the room. A latent inhibition procedure would confine the rats to the maze arms that were subsequently to be used for the training trials, so that they would experience the unique cues associated with each arm at different times. We are presently investigating this type of preexposure, and preliminary findings suggest that it is probably not equivalent to the exploratory form of preexposure used in the present study. Accordingly, a complete examination of the relationship of the present phenomenon to latent inhibition will have to await the results of these ongoing studies.

In contrast to its effect when given prior to preexposure, the administration of MK- 801 before the training trials or the test trial eliminated the CCP. Since the rats in these groups did not receive preexposure to the maze, and since lesions of the hippocampal system either have no effect on or facilitate CCP learning (McDonald \& White, 1993; White \& McDonald, 1993), it is unlikely that these effects can be attributed to actions of the drug on this system. Since lesions of the lateral nucleus of the amygdala eliminate the CCP, however, it is possible that these effects of the drug could have been due to an effect on NMDA receptors in the amygdala. This assumption leads to the tentative conclusion that blockade of NMDA receptors in the amygdala may prevent both acquisition and expression of the food CCP.

The design of the present experiment corresponds to that used in experiments on state-dependent learning. Most obviously, in the training and testing groups, rats were given a drug during training but were tested in a drug-free state, and vice versa. Even the preexposure group could be said to have learned about the maze environment under the influence of the drug, but to have expressed this information by suppressing $\mathrm{CCP}$ acquisition during the training trials in a drug-free state. Although an influence of state-dependence on the present findings cannot be completely ruled out, it is unlikely that it had a major influence on the results. Statedependent learning is produced most effectively by depressants, such as sodium pentobarbital, but much less so by stimulants, such as atropine and amphetamine (Overton, 1966). As shown by the effects of MK-801 on activity levels in the present experiment (during the preexposure and test conditions), MK- 801 is a stimulant and is therefore likely to produce weak state-dependent learning effects. Consistent with this conclusion, when rats were trained on a hippocampus-dependent radial maze task in a drug-free state, their performance was not affected when they were tested under the influence of MK-801. Conversely, the performance of rats trained under the influence of MK- 801 was unaffected when they were subsequently tested in a drug-free state (Caramanos \& Shapiro, 1994; Shapiro \& Caramanos, 1990; Shapiro \& O'Connor, 1992). In these experiments, the drug dose, route of delivery, and the strain, age, and sex of the rats were the same as in the present study. The absence of state-dependence in these experiments makes it difficult to attribute the results of the present study to this phenomenon. These findings also argue against the possibility that drug-produced perceptual or sensorimotor deficits account for the present results.

MK-801 itself has been reported to produce CCPs (Steinpreis, Kramer, Mix, \& Piwowarczyk, 1995). However, two reasons suggest that this property of the drug did not affect the results of the present study. First, the lowest dose of MK-801 that produced a CCP in that study was $0.1 \mathrm{mg} / \mathrm{kg}$; a dose of $0.05 \mathrm{mg} / \mathrm{kg}$, in the range of the dose used in the present study, did not produce a CCP. (There is a report that $0.03 \mathrm{mg} / \mathrm{kg}$ MK-801 produced a CCP [Layer, Kaddis, \& Wallace, 1993], but the use of an unbalanced CCP paradigm make this an unreliable finding.) Second, in the present study, the drug was given before both food and no-food training trials. Therefore, even if it retained some minor CCP-producing properties at the dose used, these would not have created a tendency to prefer either of the compartments.

Several other recent reports on the effects of MK-801 on CCP learning present an inconsistent picture of its effects. Thus, this drug failed to block acquisition of an amphetamine CCP (Hoffman, 1994), blocked acquisition of a morphine CCP (Tzschentke \& Schmidt, 1995), and blocked acquisition but not expression of a cocaine CCP (Cervo \& Samanin, 1995). In the latter study, expression of the cocaine CCP was blocked by the AMPA/ kianate receptor antagonist, CNQX.

The suggestion that NMDA receptor blockade may eliminate both acquisition and expression of the food 
CCP is not consistent with the effects of this treatment on memory tasks known to be sensitive to hippocampal lesions. For example, the same dose of MK-801 used in the present study blocked initial acquisition of win-shift learning in a radial maze, but it did not prevent continued expression of the behavior after it had been learned (Shapiro \& Caramanos, 1990). Moreover, the elimination of CCP expression by NMDA blockade is also inconsistent with the effects of MK-801 on hippocampal LTP, as discussed in the introduction.

Although LTP occurs in the amygdala (Chapman, Kairiss, Keenan, \& Brown, 1990; Racine et al., 1983), there has been some controversy over whether it is dependent on NMDA receptors (Chapman \& Bellavance, 1992; Gean, Chang, Huang, Lin, \& Way, 1993; Watanabe, Ikegaya, Saito, \& Abe, 1995). As is the case with the CCP studies cited above, studies on the effects of MK-801 and other glutamate receptor blockers on memory are inconsistent. Thus, AP-5 infused directly into the amygdala impaired acquisition, but not retention, of a discriminated approach response (Burns, Everitt, \& Robbins, 1994), but it had no effect on acquisition and impaired retention of an inhibitory avoidance task (Kim \& McGaugh, 1992). In the latter study, MK-801 had no effect on acquisition and an equivocal action on expression of inhibitory avoidance. Clearly, understanding the effects of MK-801 and the role of NMDA receptors and LTP in learning involving tasks that are affected by lesions of the amygdala presents a set of challenges for future research.

In conclusion, in the present study, NMDA receptor blockade with MK-801 during preexposure facilitated subsequent acquisition of the CCP. NMDA receptor blockade also prevented both acquisition and expression of the CCP. This pattern of findings is consistent with the hypothesis that NMDA receptors are involved in the storage of two different kinds of information, but it provides no direct information about the locations of these receptors. However, the pattern of effects observed is consistent with previous data suggesting the possibility that learning about the spatial environment of the maze during preexposure involves NMDA receptors in hippocampus and that acquiring and expressing a $\mathrm{CCP}$ involves NMDA receptors in amygdala.

\section{REFERENCES}

Abraham, W. C., \& Mason, S. E. (1988). Effects of the NMDA receptor/channel antagonists CPP and MK801 on hippocampal field potentials and long-term potentiation in anesthetized rats. Brain Research, 462, 40-46.

BlaCk, A. H., NADEL, L., \& O'KeEFE, J. (1977). Hippocampal function in avoidance learning and punishment. Psychological Bulletin, 84, $1107-1129$.

BLISs, T. V. P., \& LYNCH, M. A. (1988). Long-term potentiation of synaptic transmission in the hippocampus: Properties and mechanisms. In P. W. Lindfield \& S. A. Deadwyler (Eds.), Long-term potentiation: From biophysics to behavior (pp. 3-72). New York: Alan Liss.

Blodgett, H. C., \& McCutchan, K. (1947). Place versus response learning in the simple T-maze. Journal of Experimental Psychology, 37, 412-422.
Brown, T. H., Chapman, P. F., Kairiss, E. W., \& Keenan, C. L. (1988) Long-term synaptic potentiation. Science, 242, 724-728.

BURNS, L. H., EVERITT, B. J., \& RoBBINS, T. W. (1994). Intra-amygdala infusion of the $N$-methyl-D-aspartate receptor antagonist AP5 impairs acquisition but not performance of discriminated approach to an appetitive CS. Behavioral \& Neural Biology, 61, 242-250.

BUTChER, S. P., HA MBERGER, A., \& MORRIS, R. G. (1991). Intracerebral distribution of DL-2-amino-phosphonopentanoic acid (AP5) and the dissociation of different types of learning. Experimental Brain Research, 83, 521-526.

CADOR, M., Robrins, T. W., \& Evfritt, B. J. (1989). Involvement of the amygdala in stimulus-reward associations: Interaction with the ventral striatum. Neuroscience, 30, 77-86.

Caramanos, Z., \& Shapiro, M. L. (1994). Spatial memory and $\mathrm{N}$-methyl-D-aspartate receptor antagonists APV and MK-801: Memory impairments depend on familiarity with the environment, drug dose, and training duration. Behavioral Neuroscience, 108, 30-43.

Carr, G. D., Phillips, A. G., \& Fibiger, H. C. (1988). Independence of amphetamine reward from locomotor stimulation demonstrated by conditioned place preference. Psychopharmacology, 94, 221-226.

Cervo, L., \& Samanin, R. (1995). Effects of dopaminergic and glutamatergic receptor antagonists on the acquisition and expression of cocaine conditioning place preference. Brain Research, 673, 242-250.

Chapman, P. F., \& Bellavance, L. L. (1992). Induction of long-term potentiation in the basolateral amygdala does not depend on NMDA receptor activation. Synapse, 11, 310-318.

Chapman, P. F., Kairiss, E. W., Keenan, C. L., \& Brown, T. H. (1990), Long-term synaptic potentiation in the amygdala. Synapse, 6, 271-278.

Clugnet, M. C., \& LeDoux, J. E. (1990). Synaptic plasticity in fear conditioning circuits: Induction of LTP in the lateral nucleus of the amygdala by stimulation of the medial geniculate body. Journal of Neuroscience, 10, 2818-2824.

Coan, E. J., SaYwood, W., \& Collingridge, G. L. (1987). MK-801 blocks NMDA receptor-mediated synaptic transmission and long term potentiation in rat hippocampal slices. Neuroscience Letters, $\mathbf{8 0}$, $111-114$

Cohen, N. J., \& Squire, L. R. (1980). Preserved learning and retention of pattern-analyzing skill in amnesia: Dissociation of knowing how and knowing what. Science, 210, 207-209.

Collingridge, G. L., Kehl, S. J., \& MCLennan, H. (1983). The antagonism of amino acid-induced excitations of rat hippocampal CAl neurones in vitro. Journal of Physiology, 334, 19-31.

Damasio, A. R., \& TRANEL, D. (1990). Knowing that "Colorado" goes with "Denver" does not imply knowledge that "Denver" is in "Colorado." Behavioural Brain Research, 40, 193-200.

Davis, M. (1992). The role of the amygdala in fear and anxiety. Annual Review of Neuroscience, 15, 353-375.

Davis, M., Falls, W. A., CAMPEAU, S., \& Kim, M. (1993). Fear-potentiated startle: A neural and pharmacological analysis. Behavioural Brain Research, 58, 175-198.

Davis, S., Butcher, S. P., \& Morris, R. G. M. (1992). The NMDA receptor antagonist D2amino5phosphonopentanoate (DAPV) impairs spatial learning and LTP in vivo at intracerebral concentrations comparable to those that block LTP in vitro. Journal of Neuroscience, 12, 21-34.

Dickinson, A., \& Dawson, G. R. (1989). Incentive learning and the motivational control of instrumental performance. Quarterly Journal of Experimental Psychology, 41, 99-112.

Eichenbaum, H. (1992). The hippocampal system and declarative memory in animals. Journal of Comparative Neurology, 4, 217-231.

Eichenbaum, H., Cohen, N. J., Otto, T., \& Wible, C. G. (1992). Memory representation in the hippocampus: Functional domain and functional organization. In L. R. Squire, G. Lynch, N. M. Weinberger, \& J. L. McGaugh (Eds.), Memory: Organization and locus of change (pp. 163-204). Oxford: Oxford University Press.

Eichenbaum, H., Fagan, A., \& Cohen, N. J. (1986). Normal olfactory discrimination learning set and facilitation of reversal learning after medial-temporal damage in rats: Implications for an account of preserved learning abilities in amnesia. Journal of Neuroscience, $\mathbf{6}$, 1876-1884.

Eichenbaum, H., Fagan, A., Matthews, P., \& Cohen, N. J. (1988). 
Hippocampal system dysfunction and odor discrimination learning in rats: Impairment or facilitation depending on representational demands. Behavioral Neuroscience, 102, 331-339.

Eichendaum, H., Stewart, C., \& Morris, R. G. M. (1990). Hippocampal representation in spatial learning. Journal of Neuroscience, 10, 331-339.

ERICKSON, C. K., \& PATEL, J. B. (1969). Facilitation of avoidance learning by posttrial hippocampal electrical stimulation. Journal of Comparative \& Physiological Psychology, 68, 400-406.

FANSELOW, M. S. (1993). Associations and memories: The role of NMDA receptors and long-term potentiation. Current Directions in Psychological Science, 2, 152-156.

GAFFAN, D. (1974). Recognition impaired and association intact in the memory of monkeys after transection of the fornix. Journal of Comparative \& Physiological Psychology, 86, 1100-1109.

GAFFAN, D., \& HARRISON, S. (1989). A comparison of the effects of fornix transection and sulcus principalis ablation upon spatial learning by monkeys. Behavioural Brain Research, 31, 207-220.

Gean, P. W., Chang, F. C., Huang, C. C., Lin, J. H., \& Way, L. J. (1993). Long-term enhancement of EPSP and NMDA receptormediated synaptic transmission in the amygdala. Brain Research Bulletin, 31, 7-11.

Grover, L. M., \& TEYLER, T. J. (1990). Two components of long-term potentiation induced by different patterns of afferent activation. $\mathrm{Na}$ ture, 347, 477-479.

HaLl, G., \& PEARCE, J. M. (1979). Latent inhibition of a CS during CS-US pairings. Journal of Experimental Psychology: Animal Behavior Processes, 5, 31-42.

Hargreaves, E. L., Cote, D., \& Shapiro, M. (1997). Doses of MK801 that impair spatial learning in the radial maze attenuate primed burst potentiation in the dentate gyrus of freely moving rats. Behavioral Neuroscience, 111, 35-48.

HEALE, V., \& HARLEY, C. (1990). MK-801 and AP5 impair acquisition, but not retention, of the Morris milk maze. Pharmacology, Biochemistry \& Behavior, 36, 145-149.

Hirol, N., \& WhITE, N. M. (1991a). The amphetamine conditioned place preference: Differential involvement of dopamine receptor subtypes and two dopaminergic terminal areas. Brain Research, 552, 141-152.

Hiroi, N., \& White, N. M. (1991b). The lateral nucleus of the amygdala mediates expression of the amphetamine conditioned place preference. Journal of Neuroscience, 11, 2107-2116.

HiRsh, R. (1974). The hippocampus and contextual retrieval of information from memory: A theory. Behavioral Biology, 12, 421-444.

HIRSH, R. (1980). The hippocampus, conditional operations and cognition. Physiological Psychology, 8, 175-182.

HofFMAN, D. C. (1994). The noncompetitive NMDA antagonist MK-801 fails to block amphetamine-induced place conditioning in rats. Pharmacology, Biochemistry \& Behavior, 47, 907-912.

Huber, S. J., Shuttleworth, E. C., \& Freidenberg, D. L. (1989). Neuropsychological differences between the dementias of Alzheimer's and Parkinson's diseases. Archives of Neurology, 46, 1287-1291.

ISAACSON, R. L., \& Douglas, R. J. (1961). The effect of radical hippocampal ablation on acquisition of avoidance response. Journal of Comparative \& Physiological Psychology, 54, 625-628.

JACKSON, W. J., \& STrong, P. N. (1969). Differential effects of hippocampal lesions upon sequential tasks and maze learning by the rat. Journal of Comparative \& Physiological Psychology, 68, 442-450.

Jones, B., \& Mishkin, M. (1972). Limbic lesions and the problem of stimulus-reinforcement associations. Experimental Neurology, 36, 362-377.

Kant, G. J., Wright, W. L., Robinson, T. N., III, \& D'Angelo, C. P. (1991). Effects of MK-801 on learning and memory as assessed using a novel water maze. Pharmacology, Biochemistry \& Behavior, 39, 479-485.

KemP, J. A., Priestly, T., \& WoOdrufF, G. N. (1986). MK801, a novel, orally active anticonvulsant, is a potent, noncompetitive $N$-methylD-aspartate receptor antagonist. British Journal of Pharmacology (Supp. 89), 353

Kim, M., Campeau, S., Falls, W. A., \& Davis, M. (1993). Infusion of the non-NMDA receptor antagonist CNQX into the amygdala blocks the expression of fear-potentiated startle. Behavioral \& Neural Biology, 59, 5-8.

KIM, M., \& MCGaugh, J. L. (1992). Effects of intra-amygdala injections of NMDA receptor antagonists on acquisition and retention of inhibitory avoidance. Brain Research, $\mathbf{5 8 5}, 35-48$.

Knowlton, B. J., SQuire, L. R., \& Gluck, M. A. (1994). Probabilistic classification learning in amnesia. Learning \& Memory, 1, 106120.

Layer, R. T., Kaddis, F. G., \& Wallace, L. J. (1993). The NMDA receptor antagonist MK-801 elicits conditioned place preference in rats. Pharmacology, Biochemistry \& Behavior, 44, 245-247.

LEDoux, J. E. (1993). Emotional memory systems in the brain. Behavioural Brain Research, 58, 69-79.

Lubow, R. E. (1973). Latent inhibition. Psychological Bulletin, 79, 398-407.

LYNCH, G. (1986). Synapses, circuits and the beginnings of memory. Cambridge, MA: MIT Press.

McDonald, R. J., \& White, N. M. (1993). A triple dissociation of memory systems: Hippocampus, amygdala and dorsal striatum. $B e$ havioral Neuroscience, 107, 3-22.

McDonald, R. J., \& White, N. M. (1995a). Hippocampal and nonhippocampal contributions to place learning. Behavioral Neuroscience, 109, 579-593.

MCDonald, R. J., \& WhiTe, N. M. (1995b). Information acquired by the hippocampus interferes with acquisition of the amygdala-based conditioned cue preference (CCP) in the rat. Hippocampus, 5 , 189-197.

MCNaughton, B. L., \& Morris, R. G. M. (1987). Hippocampal synaptic enhancement and information storage within a distributed memory system. Trends in Neurosciences, 10, 408-415.

MiLner, B. (1985). Memory and the human brain. In M. Shafto (Ed.), How we know: Nobel Conference XX (pp. 31-59). San Francisco: Harper and Row.

Miserendino, M. J. D., Sananes, C. B., Melia, K. R., \& Davis, M. (1990). Blocking of acquisition but not expression of conditioned fear-potentiated startle by NMDA antagonists in the amygdala. $\mathrm{Na}$ ture, 345, 716-718.

Mishkin, M., Malamut, B., \& Bachevalier, J. (1984). Memories and habits: Two neural systems. In G. Lynch, J. L. McGaugh, \& N. M. Weinberger (Eds.), Neurobiology of human memory and learning (pp. 65-77). New York: Guilford.

Mishrin, M., \& Petri, H. L. (1984). Memories and habits: Some implications for the analysis of learning and retention. In L. R. Squire \& N. Butters (Eds.), Neuropsychology of memory (pp. 287-296). New York: Guilford.

Morris, R. G. M., ANderson, E., LynCH, G. S., \& Baudry, M. (1986). Selective impairment of learning and blockade of long-term potentiation by an $\mathrm{N}$-methyl-D-aspartate receptor antagonist, AP5. Nature, 319, 774-776.

Morris, R. G. M., Downes, J. J., Sahakian, B. J., Evenden, J. L., HEALD, A., \& RobBins, T. W. (1988), Planning and spatial working memory in Parkinson's disease. Journal of Neurology, Neurosurgery \& Psychiatry, 51, 757-766.

Morris, R. G. M., Garrud, P., Rawlins, J. N. P., \& O'KeEfe, J. (1982). Place navigation impaired in rats with hippocampal lesions. Nature, 297, 681-683.

Moscovirch, M. (1994). Memory and working with memory: Evaluation of a component process model and comparisons with other models. In D. L. Schacter \& E. Tulving (Eds.), Memory systems 1994 (pp. 269-310). Cambridge, MA: MIT Press.

Muller, D., LaRSON, J., \& LYNCH, G. (1989). The NMDA receptor-mediated components of responses evoked by patterned stimulation are not increased by long-term potentiation. Brain Research, 477, 396-399.

O'KeEFE, J., \& NADEL, L. (1978). The hippocampus as a cognitive map. Oxford: Oxford University Press.

O'Keefe, J., Nadel, L., Keightley, S., \& Kill, D. (1975). Fornix lesions selectively abolish place learning in the rat. Experimental $\mathrm{Neu}$ rology, 48, 152-166.

Olton, D. S., \& PAPAS, B. C. (1979). Spatial memory and hippocampal function. Neuropsychologia, 17, 669-682.

Olton, D. S., \& Samuelson, R. J. (1976). Remembrances of places 
past: Spatial memory in the rat. Journal of Experimental Psychology: Animal Behavior Processes, 2, 97-116.

Orbach, J., Milner, B., \& Rasmussen, T. (1960). Learning and retention in monkeys after amygdala-hippocampus resection. Archives of Neurology, 3, 230-251.

OVERTON, D. A. (1966). State-dependent learning produced by depressant and atropine-like drugs. Psychopharmacology, 10, 6-31.

PACKARD, M. G. (1989). Organization of memory in the brain: Role of caudate nucleus and hippocampus. Unpublished doctoral thesis, McGill University.

PaCkard, M. G., HiRSh, R., \& White, N. M. (1989). Differential effects of fornix and caudate nucleus lesions on two radial maze tasks: Evidence for multiple memory systems. Journal of Neuroscience, 9 , 1465-1472.

Packard, M. G., \& McGaugh, J. L. (1992). Double dissociation of fornix and caudate nucleus lesions on acquisition of two water maze tasks: Further evidence for multiple memory systems. Behavioral Neuroscience, 106, 439-446.

Petri, H. L., \& Mishkin, M. (1993). Behaviorism, cognitivism and the neuropsychology of memory. American Scientist, 82, 30-37.

Racine, R. J., Milgram, N. W., \& Hafner, S. (1983). Long-term potentiation phenomena in the rat limbic forebrain. Brain Research, 260, 217-231.

Robinson, G. S., Crooks, G. B., Shinkman, P. G., \& Gallagher, M. (1989). Behavioral effects of MK-801 mimic deficits associated with hippocampal damage. Psychobiology, 17, 156-164.

Sahakian, B. J., Morris, R. G., Evenden, J. L., Heald, A., Levy, R., Philpot, M., \& Robins, T. W. (1988), A comparative study of visuospatial memory and learning in Alzheimer-type dementia and Parkinson's disease. Brain, 111, 695-718.

SCOVILle, W. B., \& MiLNER, B. (1957). Loss of racent memory after bilateral hippocampal lesions. Journal of Neurology. Neurosurgery \& Psychiatry, 20, 11-21.

Shapiro, M. L., \& Caramanos, Z. (1990). NMDA antagonist MK-801 impairs acquisition but not performance of spatial working and reference memory. Psvchobiologv, 18, 231-243.

ShaPIRO, M. L., \& O'CONNOR, C. (1992). N-methyl-D-aspartate receptor antagonist MK-801 and spatial memory representation: Working memory is impaired in an unfamiliar environment but not in a familiar environment. Behavioral Neuroscience, 106, 604-612.

SQuire, L. R., \& Zola-Morgan, S. (1991). The medial temporal lobe memory system. Science, 253, 1380-1386.

Staubli, U., Thibault, O., Dilorenzo, M., \& Lynch, G. (1989). Antagonism of NMDA receptors impairs acquisition but not retention of olfactory memory. Behavioral Neuroscience, 103, 54-60.
Steinpreis, R. E., Kramer, M. A., Mix, K. S., \& Piwowarczyk, M. C. (1995). The effects of MK801 on place conditioning. Neuroscience Research, 22, 427-430.

Sutherland, R. J., \& Rodriguez, A. J. (1989). The role of the fornix/fimbria and some related subcortical structures in place learning and memory. Behavioural Brain Research, 32, 265-278.

Sutherland, R. J., \& Rudy, J. W. (1988). Place learning in the Morris place navigation task is impaired by damage to the hippocampal formation even if the temporal demands are reduced. Psychobiology, 16, 157-163.

Sutherland, R. J., Whishaw, I. Q., \& KolB, B. (1983). A behavioural analysis of spatial localization following electrolytic, kainate- or colchicine-induced damage to the hippocampal formation in the rat. Behavioural Brain Research, 7, 133-153.

Swartzwelder, H. S., Ferrari, C., Anderson, W. W., \& Wilson, W. A. (1989). The drug MK-80l attenuates the development, but not the expression, of long-term potentiation and stimulus train-induced bursting in hippocampal slices. Neuropharmacology, 28, 441-445.

Tolman, E. C. (1949). There is more than one kind of learning. Psychological Review, 56, 144-155.

TzschentKe, T. M., \& SchmidT, W. J. (1995). $N$-methyl-D-aspartic acid-receptor antagonists block morphine-induced conditioned place preference in rats. Neuroscience Letters, 193, 37-40.

Watanabe, Y., IKegaya, Y., Saito, H., \& ABE, K. (1995). Roles of $\mathrm{GABA}_{\mathrm{A}}, \mathrm{NMDA}$ and muscarinic receptors in induction of long-term potentiation in the medial and lateral amygdala in vitro. Neuroscience Research, 21, 317-322.

WEISKRANTZ, L. (1956). Behavioral changes associated with ablation of the amygdaloid complex in monkeys. Journal of Comparative \& Physiological Psychology, 49, 381-391.

WhiTE, N. M., \& MCDONALD, R. J. (1993). Acquisition of a spatial conditioned place preference is impaired by amygdala lesions and improved by fornix lesions. Behavioural Brain Research, 55, 269-281.

WIENER, S. I. (1993). Spatial and behavioral correlates of striatal neurons in rats performing a self-initiated navigation task. Journal of Neuroscience, 13, 3802-3817.

Willner, J., Gallagher, M., Graham, P. W., \& Crooks, G. B., JR. (1992). $N$-methyl-D-aspartate antagonist D-APV selectively disrupts taste-potentiated odor aversion learning. Behavioral Neuroscience, 106, 315-323

Yamamoto, T., \& Fujimoto, Y. (1991). Brain mechanisms of taste aversion learning in the rat. Brain Research Bulletin, 27, 403-406.

(Manuscript received August 12, 1996; revision accepted for publication December 26, 1996.) 